\title{
FUNGSI DAN MAKNA TIPOGRAFI BERMUATAN BUDAYA DALAM MERESPON KEBUDAYAAN
}

\author{
Naufan Noordyanto \\ Mahasiswa Program Magister Penciptaan dan Pengkajian Seni \\ Minat Studi Desain Komunikasi Visual, Program Pascasarjana ISI Yogyakarta \\ noordbita@gmail.com
}

\begin{abstract}
The phenomenon of the creation of digital typeface that include the charge of cultural values and local identity in the anatomy of Latin script characters created by the designer, especially in Indonesia, is understood as a thesis-antithesis pattern emerging among the public. In some people, the trend of typeface design with cultural content has been questioned about its usefulness in preserving the culture, or is regarded as a form of preservation of cultural bias.

Even among designers, the creative work of the creation of the typeface is often considered as a pattern of cultural preservation actualization into a different medium. Therefore, this study intends to offer solutive ideas as the middle of the problem by attempting to parse the meaning of creative work around the creation of typeface with cultural content in the domain of culture. Through this study, it can be seen that the creative work produced the typeface may automatically be a medium or an instrument of cultural propaganda, as well as writing instrument/language. The typefaces with cultural content that is created have a function as a medium to promote and raise awareness or to remind the audience, or just become a visual identity adapted to the culture. This means that the typeface with cultural content created not as a medium for cultural preservation directly. So it can not be regarded as cultural preservation bias or irregularities. Precisely the culture code that creatively adapted is useful as a visual sign to lead to wide knowledge of the cultural elements promoted. In other words, it could be an index that can help people to do a search, tracks, or studies on the original culture or identity.
\end{abstract}

Keywords: typeface, scripts, cultural

\section{PENDAHULUAN}

\section{Latar Belakang Masalah}

Perkembangan keaksaraan yang didukung oleh masifnya penetrasi budaya modern mengubah sistem produksi dan konsumsi terhadap aksara. Peran teknologi informasi dan komunikasi, terutama sistem komputer dan internet, memungkinkan beralihnya pola produksi, pengoperasian, dan akses aksara dari metode konvensional (melalui medium kertas, kayu, dan lainnya) ke metode digital. Hal ini bukan menafikan sepenuhnya bahwa realitanya metode konvensional masih tetap dipakai. Tetapi kecenderungan dukungan teknologi berpengaruh pada perkembangan trend tipografi, khususnya aksara dalam format digital. Apalagi keterbukaan internet, memungkinkan dukungan untuk memperluas jangkauan sosialisasi dan publikasi aksara digital, khususnya jenis aksara latin. Kehadiran 
teknologi digital mampu memberi kesempatan kepada masyarakat untuk memproduksi secara mandiri maupun berbagi-pakai aksara. Dalam konteks trend kreatif produksi aksara latin digital, teknologi informasi memungkinkan setiap orang mampu mengaktualkan dan mempopulerkan diri dan komunitas, identitas, budaya, dan peradabannya, melalui rekonstruksi ulang dalam penciptaan rupa aksara. Trend ini ditandai dengan ramai-ramai munculnya fenomena penciptaan aksara digital yang memasukkan muatan nilai-nilai budaya dan identitas lokal dalam penciptaan/desain aksara latin baru yang dibuat para kreator aksara terutama di Indonesia. Visualisasi kreatif dalam penciptaan aksara tersebut umumnya dilakukan dengan memberi penggayaan bentuk atau mengkombinasikan kode budaya atau identitas lokal yang diadaptasi ke dalam anatomi aksara latin. Sehingga muatan budaya yang representatif dalam aksara memungkinkan agar mudah dikenali sebagai bagian ekspresi identitas dan pengenalan kebudayaan.

Rupanya, ide penciptaan tersebut ternyata dipandang sebagai pola tesis-antitesis yang muncul di kalangan masyarakat. Fenomena penciptaan trend desain aksara bermuatan budaya yang demikian, di sebagian kalangan dipertanyakan kegunaannya dalam pelestarian kebudayaan atau justru dianggap sebagai bentuk bias pelestarian kebudayaan. Bahkan di kalangan masyarakat desainer sendiri, kerja kreatif penciptaan aksara tersebut seringkali dianggap sebagai pola aktualisasi pelestarian kebudayaan ke dalam medium yang berbeda.

Beranjak dari permasalahan tersebut, kajian ini penting dilakukan dalam rangka menawarkan gagasan solutif sebagai jalan tengah dari perbedaan pendapat yang berkembang dari fenomena penciptaan aksara bermuatan budaya atau identitas. Penulis berusaha mengurai dan mengungkap makna seputar kerja kreatif dan positif penciptaan aksara bermuatan budaya tersebut dalam konteks kebudayaan.

\section{Rumusan Masalah}

Adapun rumusan masalah dari penelitian ini adalah:

1. Bagaimanakah kerja kreatif penciptaan tipografi bermuatan budaya?

2. Bagaimanakah fungsi dan makna penciptaan tipografi bermuatan budaya dalam konteks kebudayaan?

\section{Batasan Penelitian}

Penelitian ini dibatasi pada obyek material berupa karya tipografi bermuatan budaya Indonesia dalam format digital. Aksara sebagai fokus perhatian tipografi, dipandang dari visualitas aksara dari konteks kebudayaan. 


\section{METODE PENELITIAN}

Metode pengumpulan data dilakukan dengan kajian pustaka Begitupula dalam pengumpulan landasan teori. Kajian ini dilakukan dengan analisis kualitatif bersifat multiparadigma dan terbuka.

Penulis dalam hal ini sebagai pengkaji, juga memposisikan diri sebagai praktisi dalam tipografi bermuatan budaya. Artinya, cara pandang dan pengalaman subyektif dalam praktik desain, berperan penting dalam upaya mengungkap makna dan menawarkan gagasan solutif sebagai jalan tengah dari perbedaan pendapat yang berkembang, khususnya dalam kerja kreatif dan positif penciptaan aksara bermuatan budaya tersebut dalam konteks kebudayaan.

\section{HASIL PENELITIAN DAN PEMBAHASAN}

\section{Perkembangan tipografi bermuatan budaya}

Tipografi bermuatan budaya maksudnya merujuk pada aksara yang dirancang dengan memberi muatan kode budaya atau identitas lokal ke dalam anatomi aksara, khususnya aksara latin. Hasil visualisasi penggayaan bentuk aksara inilah kemudian disebut sebagai typeface, yakni perwajahan atau rupa (face) aksara (type), karakteristik, keunikan, dan perbedaan yang terbentuk di dalam rancangan karakter aksara, sehingga memberikan keterbedaan dengan jenis aksara yang lain. Umumnya, dewasa ini hasil akhir kerja kreatif tersebut berwujud aksara elektronik/digital atau yang dikenal sebagai font yang dapat dibagi-pakai melalui sistem komputer. Font mengacu pada satu set (dalam satu style atau varian: roman/regular, italic, atau bold) karakter lengkap aksara atau typeface dalam bentuk digital yang bisa diatur dalam skala dan ukuran tertentu (Strizver, 2006: 31). Selain itu, kerja kreatif mewujudkan tipografi bermuatan budaya juga dilakukan untuk kebutuhan lain, misalnya untuk identitas visual tertentu yang bercorak budaya lokal, misalnya dalam bentuk logo, headline poster, dan lainnya.

Pada perkembangannya, kini sudah banyak tersaji berbagai bentuk aksara terutama typeface bermuatan budaya baik di lingkup internasional hingga Indonesia, mulai dari modifikasi bentuk yang sederhana hingga secara ekstrim dianggap "merusak" performa aksara sebagai perangkat baca, mulai sebagai sepaket font maupun hanya logotype atau identitas saja. Dunia Tipografi tidak lagi terbatas pada keperluan baca tulis namun sudah menjadi obyek eksplorasi seni secara luas. Geliat penciptaan typeface bermuatan budaya tidak hanya dilakukan di lingkungan industri namun juga di lingkungan akademis.

Beberapa karya tipografi bermuatan budaya, baik dalam wujud typeface maupun 
identitas visual yang berhasil teridentifikasi di antaranya sebagaimana dapat diperhatikan pada gambar 1-32. Kode kebudayaan yang diusung dalam pola penciptaan tipografi dapat diidentifikasi dari data visual tersebut meliputi kode kebudayaan desain aksara lokal atau kode kebudayaan di luar aksara, seperti ukiran, senjata, batik, dan lain-lain.

Menyimak trend penciptaan aksara latin bermuatan budaya yang telah dilakukan selama ini, para kreator aksara berupaya memberi identitas atau budaya lokal terhadap aksara latin (sebagai bentuk aksara dasar). Modifikasi rupa aksara diidentifikasi dari karakter dan unsur khas adaptasi budaya yang direpresentasikan. Hal ini mirip dengan kerja "apropriasi”, yaitu "menjadikan sesuatu yang asing menjadi milik sendiri” (Ricoeur, 2012: 95). Aksara latin, yang diasosiasikan sebagai representasi budaya modern, global, dan dari Barat, dijadikan "milik sendiri" dengan dibubuhi muatan identitas lokal dari adaptasi kebudayaan sendiri (Indonesia). Tetapi istilah "milik sendiri" dimaknai sebagai "meminjam kebudayaan asing tersebut (aksara latin) untuk diadaptasi, dimodifikasi, dan dipakai dalam arena lokal”, bukan sepenuhnya dimiliki.

Maka, dalam konteks kebudayaan Indonesia, upaya penciptaan tersebut, lebih dekat sebagai bentuk akulturasi kebudayaan, dengan strategi "lokalisasi aksara latin" atau memberi identitas lokal pada aksara latin. Sebagai ilustrasi, misalnya kreasi aksara latin yang digayakan menyerupai aksara Jawa, bisa dikatakan sebagai upaya "men-Jawa-kan" aksara Latin atau memberi identitas lokal dari sisi penggayaan aksara latin. Sementara memberi identitas suatu aksara latin dengan elemen visual berupa motif batik, canting, ukir-ukiran atau ragam hias, senjata, dan lain sebagainya dianggap sebagai upaya mempertemukan aksara dengan hal-hal yang tidak ada hubungannya dengan aksara. Sehingga upaya ini lambat laun akan memperkaya keaksaraan dengan berbagai corak yang khas, terutama kaitannya dengan identitas dan budaya dari Indonesia.

Bentuk penciptaan tersebut dapat dikatakan sebagai upaya merupa aksara dengan mengacu pada kode muatan budaya atau unsur identitas tertentu sebagai ide penciptaan. Merupa aksara dianggap sebagai cara memandang melalui dimensi estetik aksara atau mengutamakan unsur seni dalam aksara (Widiatmoko, dkk., 2010: 101). Artinya dalam hal ini, dimensi estetik aksara diolah dengan mengeksplorasi anatomi aksara latin berdasarkan kode budaya atau identitas lokal yang diadaptasi. Dimensi estetik aksara dinarasikan dalam sudut pandang materi dan pengetahuan tentang kebudayaan yang diusung. 
Tantangannya adalah butuh keahlian khusus dan pemahaman teknologi untuk mensejajarkan keaksaraan bermuatan budaya lokal Indonesia dengan aksara lain di dunia. Meski teknologi digital mampu menawarkan dukungan teknis dalam penciptaan typeface, yang tidak kalah penting adalah riset dan eksplorasi yang mendalam mengenai asal-usul muatan budaya yang direpresentasikan. Tentu dalam hal ini, desainer typeface dituntut memiliki dua sudut pemahaman yang mendalam, di satu pihak harus memahami konsep budaya dan konten lokal tersebut, di pihak lain dituntut pemahaman terhadap Tipografi Latin.

Selain itu, estetika aksara yang menjadi perhatian merupa aksara, mestinya tidak hanya berkutat seputar tampilan visual (fisik), tetapi juga fokus pada kesan atau nuansa (nonfisik) lokal yang dimunculkan dari tampilan visual aksara tersebut. Oleh Sihombing (2001: 66), interpretasi kesan yang ditangkap tersebut merupakan "asosiasi terhadap realita yang didapat berbagai macam referensi dan rekaman berbagai pengalaman". Dalam hal ini, yaitu referensi dari kode kebudayaan dan identitas lokal yang direpresentasikan.

\section{Kode penciptaan tipografi bermuatan budaya}

Lazimnya akulturasi kebudayaan, bentuk-bentuk pola adaptasi kode budaya dan identitas lokal dilakukan dengan mempertemukan kebudayaan satu dengan kebudayaan lain, menjadi typeface latin baru. Kreasi merupa aksara tersebut pada dasarnya mempertemukan aksara latin dengan kode kebudayaan di luar aksara Latin. Kode kebudayaan tersebut dalam proses kreatif desain aksara, dikategorikan sebagai kode penciptaan berikut (Widiatmoko dkk: 2010: 101): Pertama, Penciptaan typeface dengan mempertemukan dua aksara, yaitu aksara latin dengan aksara lain bercorak lokal (etnik); dan Kedua, Penciptaan typeface dengan mempertemukan aksara latin dengan hal-hal di luar aksara.

Kode penciptaan pertama, penciptaan typeface dengan mempertemukan dua aksara, meliputi aksara latin dengan aksara lain bercorak lokal (etnik), didefinisikan sebagai upaya "melokalkan" aksara latin dengan mengambil sisi penggayaan aksara lokal (etnik), atau aksara latin dikreasikan dengan gaya aksara lokal. Sebagaimana misalnya aksara Jawa yang diambil sisi penggayaannya untuk diterapkan pada anatomi aksara latin, menghasilkan typeface latin dengan karakteristik rupa aksara Jawa. 
Istilah "melokalkan" yang hanya ditasbihkan pada kode penciptaan pertama oleh Widiatmoko tersebut, jika mengacu pada usaha memberi identitas lokal pada aksara latin, menurut penulis kurang pas. Karena baik kode penciptaan pertama dan kedua pada dasarnya sama-sama dianggap memiliki esensi "melokalkan" aksara latin baik secara tampilan visual (fisik/material) maupun dari segi kesan (nonfisik) yang dimunculkan. Atau lebih tepatnya "melokalisasi aksara latin" sebagaimana penulis uraikan sebelumnya.

Sementara pada kode penciptaan kedua, penciptaan typeface dengan mempertemukan aksara latin dengan hal-hal di luar aksara, didefinisikan sebagai upaya memberi identitas atau tema tertentu pada aksara latin. Identitas dan kode budaya yang memungkinkan untuk diadaptasi pada aksara latin dapat bersifat material/fisik atau nonfisik. Kode budaya dan identitas yang bersifat fisik, misalnya unsur visual batik, senjata tradisional, ukiran, dan lain-lain, dapat diterapkan dan dieksplorasikan pada aksara latin. Sedangkan kode budaya dan identitas nonfisik meliputi tema, nilai-nilai tradisi, dan personality, dan lain-lain, dari suatu identitas tertentu, dapat pula dieksplorasi dalam anatomi aksara. Sebagai ilustrasi, misalnya typeface bercorak Madura dapat diciptakan dengan ide karakter visual yang lancip/tajam, tegas, sederhana, untuk merepresentasikan karakter dan stereotype kepribadian masyarakat Madura yang tegas dan sederhana.

\section{Tipografi bermuatan budaya dalam konteks kebudayaan}

Dukungan teknologi memungkinkan setiap orang dapat mengaktualkan dan mempopulerkan diri, komunitasnya, budayanya, melalui eksplorasi rupa aksara. Fenomena masifnya penciptaan beragam typeface latin bermuatan budaya tersebut, dipahami sebagai suatu cara bagaimana identitas lokal berpartisipasi di ruang global. Hal ini mengindikasikan kesadaran akan budaya-budaya lokal di tengah dominasi kecenderungan modernisasi dan globalisasi. Bahkan, kesadaran mengenalkan identitas budaya bangsa melalui eksplorasi Tipografi sudah dilakukan oleh (desainer) negaranegara lain seperti Cina, Jepang, India, Arab, dan lain-lain, misalnya dengan menciptakan desain typeface dengan penggayaan aksara lokal mereka. Begitu pula, para kreator aksara di Indonesia, juga ikut serta ramai-ramai mengangkat budaya lokal sebagai ide penciptaan typeface latin.

Memperhatikan praktik yang demikian, aksara yang diciptakan menjadi lebih dari sekedar instrumen bahasa verbal. Visualitas aksara yang diciptakan juga memiliki fungsi “menampilkan” kode budaya yang diusung. 
Dari sisi modus penciptaan, praktik ini bisa jadi didasari karena ekspresi seni semata, maupun kebutuhan fungsional tertentu, misalnya mau mengenalkan kode budaya dan identitas lokal yang direpresentasikan dalam aksara. Atau justru untuk sebuah kepentingan menyatakan identitas tertentu, misal untuk logo, headline poster, dan lain-lain.

Dalam konteks resistensi terhadap budaya dominan, kesadaran akan budaya lokal yang diangkat dalam penciptaan aksara, bermaksud membantu merawat kelangsungan eksistensi identitas dan budaya lokal di tengah penetrasi masif dari budaya global/luar. Merupa aksara bermuatan budaya yang kurang dikenal atau hampir ditinggalkan akan membantu budaya tersebut dikenal khalayak. Begitu juga jika kebudayaan tersebut telah dikenal luas, muatan budaya yang direpresentasikan pada aksara akan semakin mempertahankan eksistensi di ranah global. Tentu saja jika aksara tersebut terus disosialisasikan, apalagi jika berhasil dibagipakai secara masif.

Dalam konteks ke-Indonesia-an (nasional), krisis identitas budaya merupakan permasalahan besar yang menyangkut kewibawaan suatu bangsa, terlebih lagi ketika terjadi klaim-klaim aset budaya dari pihak tak bertanggungjawab yang menunjukkan hilangnya segi-segi kebangsaan dan kecintaan pada budaya sendiri, sehingga menimbulkan keacuhan pada diri warga negaranya. Dan jika dibiarkan berlarut-larut, maka bangsa Indonesia akan kehilangan jati dirinya, bahkan menjadi pengekor dari budaya asing. Sehingga ekplorasi typeface ini menjadi menarik, penting untuk dihadirkan dan diangkat kembali. Penciptaan tipografi bermuatan budaya dianggap sebagai suatu bentuk kreatifitas yang usefull dan implementatif yang sesuai dengan konsumsi masyarakat modern yang erat dan dekat dengan budaya komunikasi verbal dan visual sebagai bagian kehidupan sehari-hari.

Dengan demikian, aksara tersebut dengan sendirinya dapat menjadi medium atau instrumen propaganda budaya, selain sebagai instrumen tulis/bahasa. Karena sebagaimana dalam Widiatmoko, dkk. (2010: 117-118), eksplorasi Tipografi mampu menyikapi isu-isu bertema kebudayaan dan kebangsaan. Kerja penciptaan tipografi bermuatan budaya pada dasarnya merupakan upaya mendukung pelestarian budaya lokal dalam medium berbeda yang disesuaikan dengan kondisi terkini.

Hal ini juga mengingat trend kreatif mengekplorasi typeface bernuansa budaya juga tiada habisnya dilakukan oleh negara lain. Seperti negara Jepang dan Cina, dimana popularitas dari aksara-aksara (latin) 
bernuansa budayanya menjadi ajang kreativitas tidak hanya di negerinya sendiri, namun identitas kebangsaannya tetap terjaga. Begitu juga font bernuansa budaya dengan penggayaan bentuk aksara India atau Thailand yang memiliki kemiripan karakter visual dengan aksara Jawa. Karakter budaya yang sangat khas diolah dalam eksplorasi Tipografi yang kemudian dipenetrasikan secara global dengan dukungan teknologi informasi, menjadikan negara-negara tersebut semakin mendapatkan pengakuan akan identitas budayanya di mata dunia, sehingga menjadi dikenal luas dan mengglobal, menembus batas ruang dan waktu. Begitu juga dengan negaranegara belahan dunia lainnya, juga ikut serta memperkaya eksplorasi Tipografinya dengan mengangkat berbagai unsur lokal khas daerah masing-masing, seperti Arab, Rusia, dan masih banyak yang lain. Hal inilah yang menjadi keunikan Tipografi, dalam desain aksara dapat diberi muatan unsur-unsur budaya lokal.

Di sisi lain, sejak dahulu Indonesia sudah memiliki tradisi menulis yang dibuktikan dengan berbagai prasasti dan naskah-naskah kuno dengan tulisan bernuansa budaya (asli), misalnya tulisan dengan aksara Pallawa, Jawa, dan lain-lain. Namun, sulitnya mempertahankan tradisi tersebut agar tetap terjaga dari masa ke masa serta mengikuti perkembangan teknologi yang ada, membuat warganya berpikir ulang mencari alternatif solusi agar identitas bangsa Indonesia tetap mendapat pengakuan di mata bangsanya sendiri dan belahan bumi lain. Misalnya dalam konteks kajian ini, yaitu menciptakan desain typeface latin dengan penggayaan aksara etnik tersebut.

Berbeda lagi, jika unsur budaya yang diangkat dalam eksplorasi typeface tidak ada hubungan langsung dengan tradisi menulis kaitannya aksara aksara kuno asli yang memang sudah jarang digunakan, seperti unsur-unsur budaya berupa karakter visual rumah adat, ukiran, senjata pusaka, dan lain sebagainya, selain dilakukan dengan pendekatan ekplorasi Tipografi, tentu saja juga harus tidak dengan meninggalkan pelestarian budaya lokal tersebut.

Dari ulasan di atas, maka penting dipahami, bahwa aksara bermuatan budaya yang diciptakan berfungsi sebagai medium untuk mengenalkan, mensosialisasikan, dan menumbuhkan kesadaran, mengingatkan kepada khalayak, atau justru menjadi identitas visual terhadap kebudayaan yang diadaptasi. Artinya, aksara bermuatan budaya tersebut diciptakan bukan sebagai medium pelestarian kebudayaan secara langsung, melainkan hasil eksplorasi tipografi yang demikian adalah instrumen atau medium untuk meningkatkan 
awareness khalayak terhadap unsur muatan budaya yang diusung. Beban dan tugas konservasi kebudayaan belum selesai dengan terciptanya desain-desain aksara latin yang diberi muatan kebudayaan tersebut tanpa upaya konservasi langsung pada unsur muatan budaya yang diusung. Sehingga praktik penciptaan tipografi yang demikian tidak bisa dianggap sebagai bias atau penyimpangan pelestarian kebudayaan. Justru kode kebudayaan yang diadaptasi secara kreatif berfungsi sebagai tanda visual untuk mengarahkan pada ragam pengetahuan tentang unsur budaya yang diusung. Dengan kata lain, ia dapat menjadi indeks yang bisa membantu khalayak untuk melakukan penelusuran, pelacakan, ataupun studi budaya atau identitas aslinya (Widiatmoko, 2010: 137).

Di samping itu, kaitannya dengan aksara etnik lokal, penciptaan tipografi latin mengadaptasi penggayaan aksara etnik lokal, bukan bermaksud merusak esensi aksara etnik tersebut, dan bukan juga bias pelestarian budaya. Eksplorasi aksara bermuatan budaya yang dilakukan adalah justru upaya alternatif yang dilakukan beriringan dengan misi pelestarian aksara asli secara langsung. Kehadirannya dapat membantu dalam pengenalan, sosialisasi, dan meningkatkan kesadaran khalayak terhadap aksara etnik sebagai identitas dan budaya lokal. Karena adaptasi penggayaan aksara etnik yang dimediumisasi ke dalam aksara latin, memungkinkan untuk dapat diterima secara universal dan tidak hanya bersifat lokal. Mengingat aksara latin penetrasi dan penggunaannya bersifat global, di berbagai negara dan media. Sehingga kondisi positif ini membantu dalam penetrasi (sosialisasi) kebudayaan yang diusung.

\section{KESIMPULAN}

Tidak hanya sekedar instrumen bahasa verbal, visualitas aksara bermuatan budaya yang diciptakan juga memiliki fungsi “menampilkan" kode budaya yang diusung. Kesadaran akan budaya lokal yang diangkat dalam penciptaan aksara, bermaksud membantu merawat kelangsungan eksistensi identitas dan budaya lokal di tengah penetrasi masif dari budaya global/luar. Sehingga ekplorasi typeface ini menjadi menarik, penting untuk dihadirkan dan diangkat berkelanjutan. Penciptaan tipografi bermuatan budaya dianggap sebagai suatu bentuk kreatifitas yang usefull dan implementatif yang sesuai dengan konsumsi 
masyarakat modern yang erat dan dekat dengan budaya komunikasi verbal dan visual sebagai bagian kehidupan sehari-hari.

Geliat penciptaan aksara bermuatan budaya yang diciptakan berfungsi sebagai medium untuk mengenalkan, mensosialisasikan, dan menumbuhkan kesadaran, mengingatkan kepada khalayak, atau justru menjadi identitas visual terhadap kebudayaan yang diadaptasi. Artinya, aksara bermuatan budaya tersebut diciptakan bukan sebagai medium pelestarian kebudayaan secara langsung. Sehingga tidak bisa dianggap sebagai bias atau penyimpangan pelestarian kebudayaan. Justru kode kebudayaan yang diadaptasi secara kreatif berfungsi sebagai indeks yang bisa dilacak budaya atau identitas aslinya.

Selain itu, kaitannya dengan aksara etnik lokal, penciptaan tipografi latin mengadaptasi penggayaan aksara etnik lokal, bukan bermaksud merusak esensi aksara etnik tersebut, dan bukan juga bias pelestarian budaya. Eksplorasi aksara bermuatan budaya yang dilakukan adalah justru upaya alternatif yang dilakukan beriringan dengan misi pelestarian aksara asli secara langsung. Karena adaptasi penggayaan aksara etnik yang dimediumisasi ke dalam aksara latin, memungkinkan untuk dapat diterima secara universal dan tidak hanya bersifat lokal.

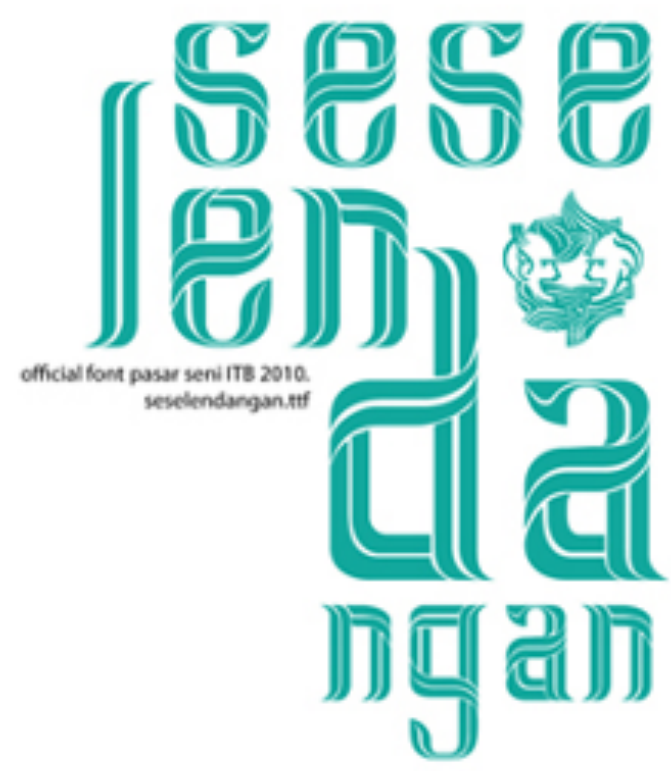

Gambar 1 Typeface seselendangan karya Azmi Kamarullah, diciptakan sebagai official font Pasar Seni Institut Teknologi Bandung, 2010. Sebuah upaya memberi identitas lokal dengan mengakomodasi penggayaan aksara mengikuti bentuk selendang Sumber:

http://www.desainstudio.com/2011/o4/kumpulan-fontkhas-indonesia-karya-anak.html

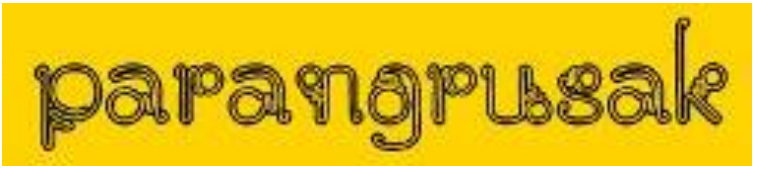

Gambar 2 Typeface Parangrusak karya Imam Zakaria, upaya memberi identitas lokal pada aksara latin mengakomodasi penggayaan aksara mengikuti bentuk modul batik Parangrusak.

Sumber: http://www.dafont.com/parangrusak. font)

\section{Sampurasun}

Gambar 3 Typeface CW Ciung Wanara oleh Andriansyah, 2012, upaya memberi identitas lokal mengakomodasi penggayaan mengikuti bentuk senjata tradisional kujang Sumber: dafont.com 


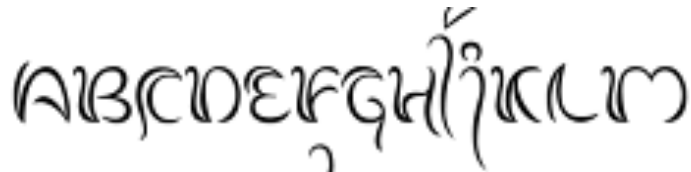

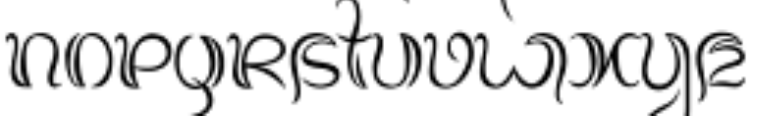

Gambar 4 Typeface Balinese dengan penggayaan aksara Bali

Sumber: http://www.ffonts.net/Balinese-FamilyNormal.font

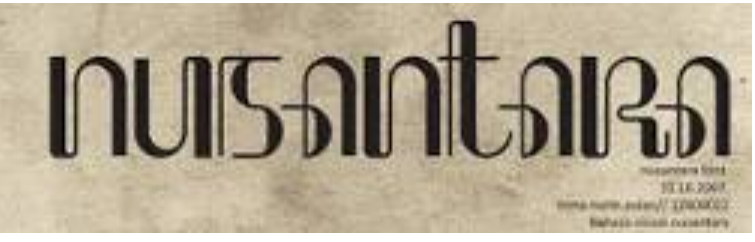

Gambar 5 Typeface Nusantara mengakomodasi penggayaan aksara Jawa

\section{Sumber:}

http://www.desainstudio.com/2011/04/kumpulanfont-khas-indonesia-karya-anak.html

\section{abcdefghijklm nopqrstuvwx}

Gambar 6 Gambar 6. Typeface Garuda oleh Andy Aw Masry, terinspirasi dari garis, bentuk, dan gaya simbol Garuda Pancasila Sumber:

http://www.myfonts.com/fonts/aawm/garuda/
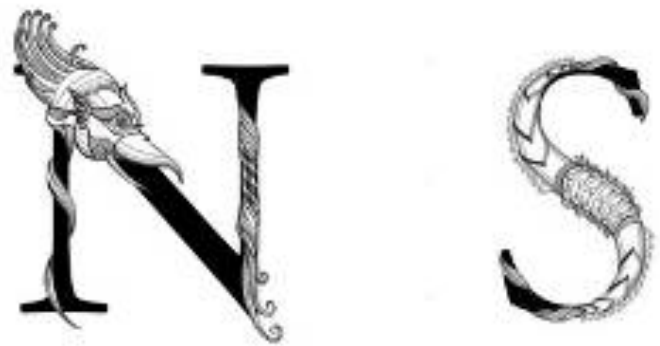

Gambar 7 Typeface Balinese Deva oleh Haris Mustafa, desainer asal bandung, 2011, upaya memberi identitas lokal pada aksara latin berupa karakter visual makhluk mitologi kepercayaan masyarakat Bali yang diterapkan pada aksara dasar (typeface) Garamond.

Sumber:

https://www.behance.net/gallery/2107228/BalineseDeva

\section{Boutipues of Pepouke}

Gambar 8 Typeface Boutiques of Merauke oleh Adien Gunarta, 2013, mengakomodasi bentuk ragam hias Papua

Sumber:

http://www.fontspace.com/gunarta/boutiques-ofmerauke

\section{BATคKคRT ANT Cシㄴㅋㅌㅊ}

Gambar 9 Typeface Batu Harang, diciptakan oleh Njoo Dewi Candra Kertasari, penggayaan aksara latin mengakomodasi bentuk aksara Batak kuno. Sumber: Surianto Rustan, S.Sn. 2011. Font \& Tipografi. Jakarta: PT. Gramedia Pustaka Utama

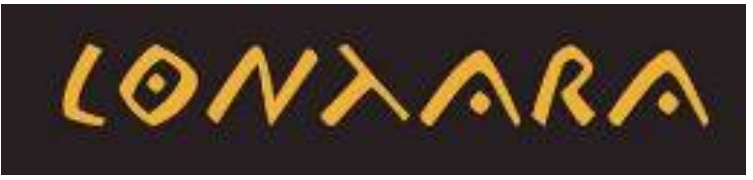

Gambar 10 Typeface Lontara oleh Triden Works, 2011, penggayaan aksara latin mengakomodasi bentuk aksara Lontara Bugis.

Sumber:

http://lontaratypeface.blogspot.com/2011/06/nusanta ra-original-lontara-typeface.html

\section{barong typeface}

Gambar 11 Typeface Barong, oleh Anneisa Azhoera, 2014, terinspirasi dari karakter visual Barong Bali. Sumber:

https://www.behance.net/gallery/14867297/BarongTypeface 


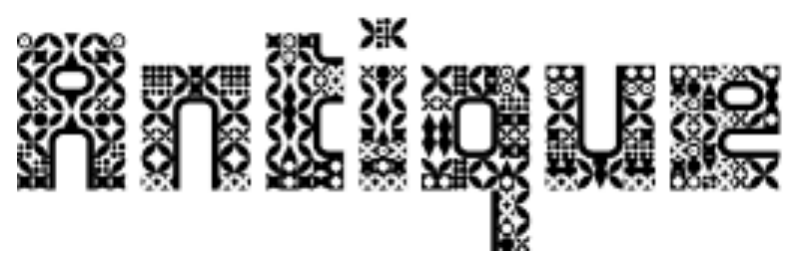

Gambar 12 Typeface Antique Paleoindonesia oleh Adien Gunarta, 2012, mengakomodasi motif batik Indonesia (tidak diketahui motif asal daerah mana). Sumber: http://www.fontspace.com/gunarta/antiquepaleoindonesia

$A B C D E, \mathbb{F}$ HI I IT I III n O p q R 5 t $\checkmark$ w 2. 3456789 . , ! ?

Gambar 13 Typeface Jawa Palsu, dengan penggayaan aksara Jawa

Sumber: dafont.com

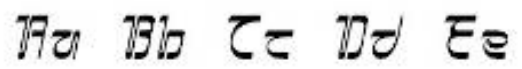

FF $\mathrm{Gg}$ Hh $7 i \mathrm{Jj}$

Kk $2177 m$ ग17

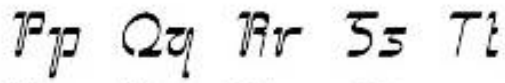

Uv vv Wu $x_{x}$

$y y z=0 \begin{array}{llllll} & 1 & 2 & 3 & 4\end{array}$

$56780 . . ?$

? $E$

Gambar 14 Typeface Sangkuriang dengan penggayaan aksara Sunda

Sumber: http://www.dafont.com/sangkuriang.font

\section{ABCOEF E III \\ $J$ K L M N OPQ \\ RS I U VWXY \\ ZO1Z34567 \\ 89.178}

Gambar 15 Typeface Minangkabau oleh Suryo Wahono, mengadaptasi bentuk atap rumah adat Minangkabau

Sumber: http://www.dafont.com/minangkabau.font

ABCAEFGHIJ

KLMNOPQR

STUUWKYZ

Gambar 16 Typeface Jepara oleh David Ogama, 2013

Sumber: Laporan Tugas Akhir Perancangan, DKV

ISI Yogyakarta, 2013

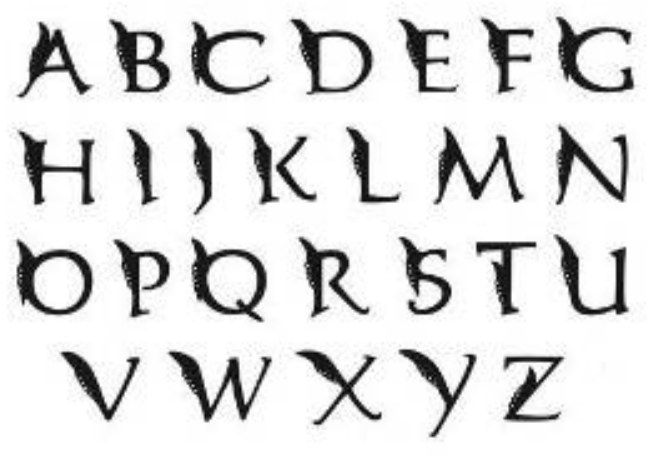

Gambar 17 Typeface Calligrang oleh Jihad Yanuar, 2013, terinspirasi dari karakter visual senjata tradisional kujang dari Jawa Barat.

Sumber: http://luc.devroye.org/JihadYanuarCalligrang-2013.jpg 


\section{Pa $\mathrm{Bb} \mathrm{Co} \mathrm{Dd}$ \\ Ee Ff Gy Hh li \\ Jj $\mathrm{Kh} \mathrm{ll} \mathrm{Mm}$ \\ nn Do Pp Qq \\ Rr Ss Tt Uu \\ vo Uw $X x$ \\ Yy Zz 0123 \\ $456789 .$, !}

Gambar 18 Typeface Nusantara, oleh Prima Aditya, mengadaptasi bentuk-bentuk ikonik wayang.

Sumber: Laporan Tugas Akhir Perancangan, DKV ISI Yogyakarta, 2012

\section{GUNUNGAN TYPEFACE}

Gambar 19 Typeface Gunungan Typeface oleh Dimas Dwi, 2014, terinspirasi dari bentuk wayang Gunungan. Sumber:

https://www.behance.net/gallery/16658545/Gununga n-Typeface

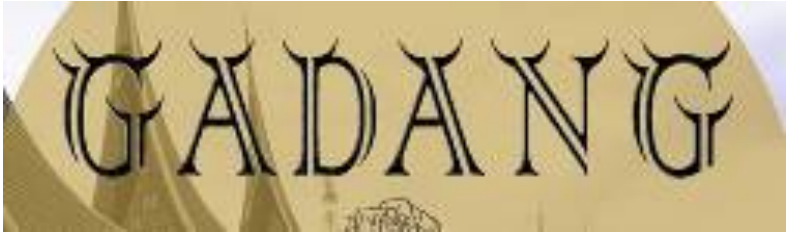

Gambar 20 Typeface Typeface Gadang oleh Dani

Teguh, 2014, terinspirasi dari karakter visual rumah Gadang, Padang.

Sumber:

https://www.behance.net/gallery/13962585/GADAN G-FONT
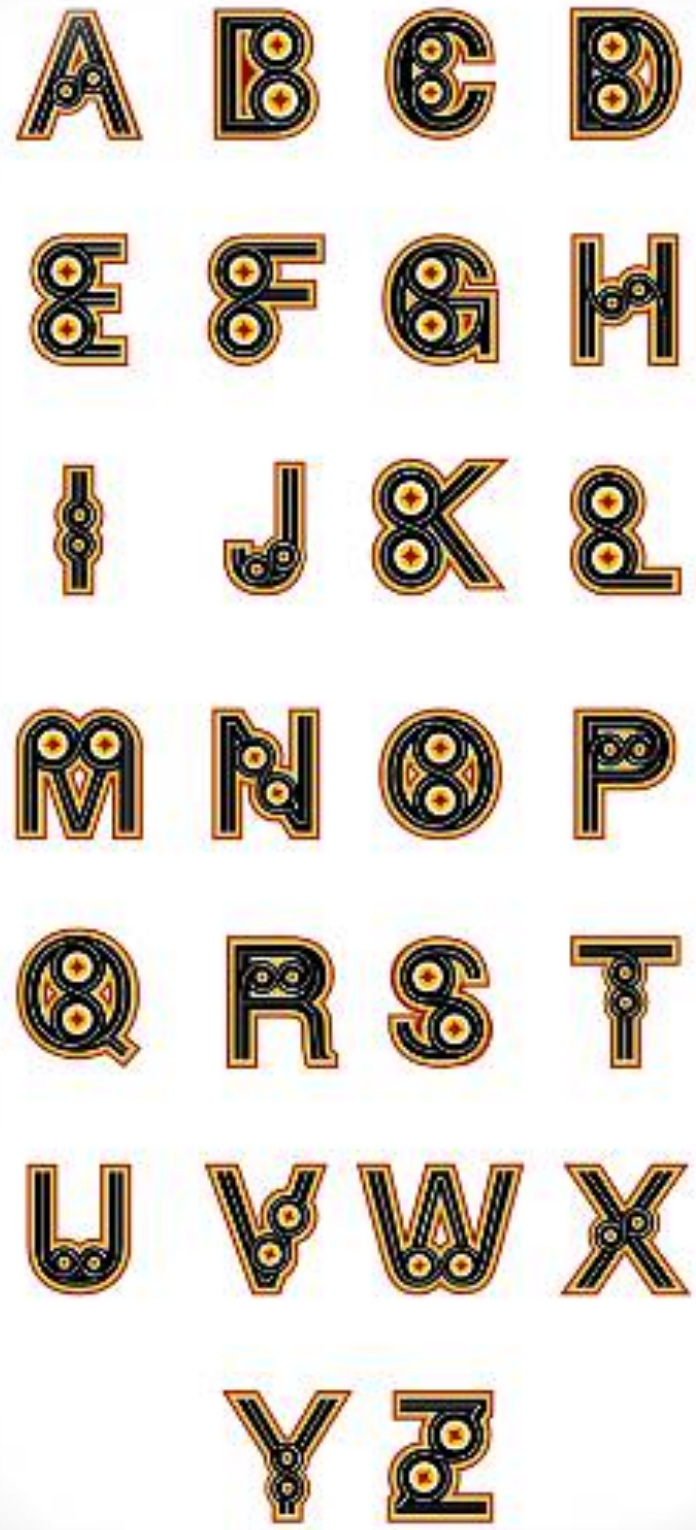

Gambar 21 Typeface Akkala' Pa'ssura. Typeface oleh Annisa Luthfiasari, 2013, terinspirasi ornamen ukir Toraja.

Sumber:

https://www.behance.net/gallery/16086733/KutaiTypeface 


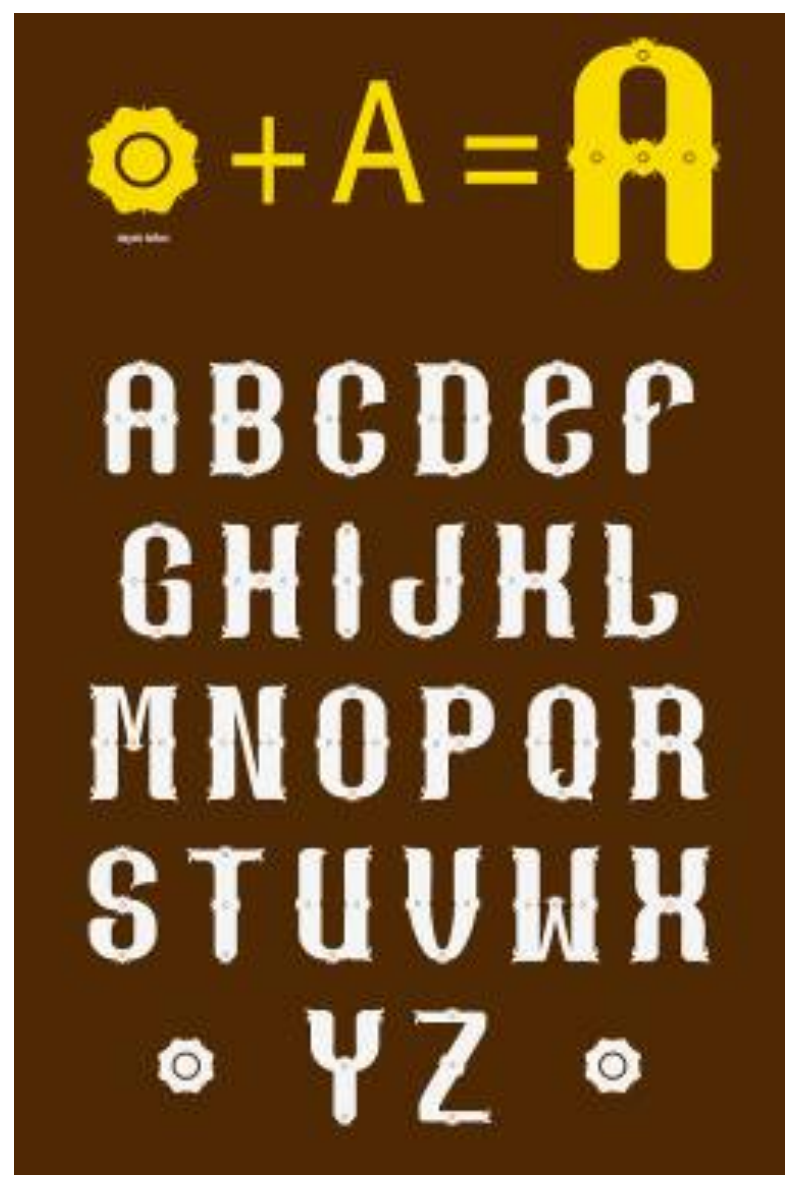

Gambar 22 Typeface Kalimantan, mengadaptasi ikon tatto etnis Dayak Kalimantan Sumber:

http://www.behance.net/gallery/Kalimantanfont/11425621

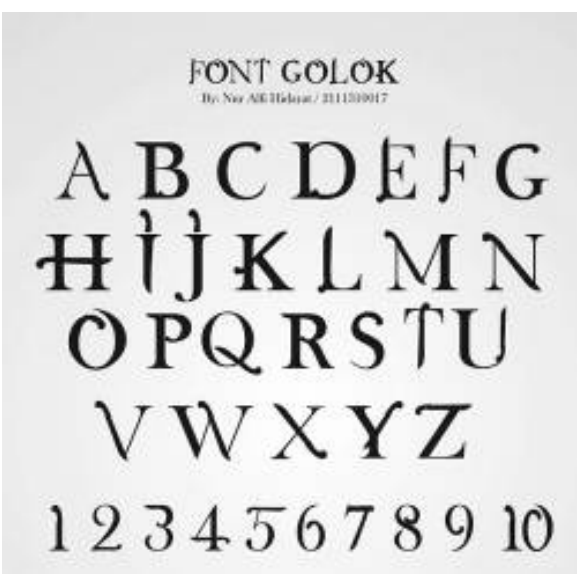

Gambar 23 Typeface Golok oleh Nur Alfi Hidayat, 2013, terinspirasi dari senjata tradisional golok. Sumber: http://luc.devroye.org/NurAlfi-FontGolok2013.jpg

\section{Aa Bb Cc )d Ee

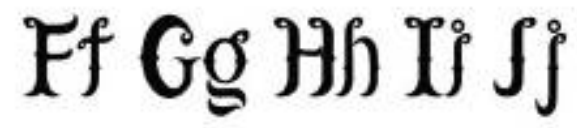 CKL L Mm Non 0o Pp Qq Rr Ss Tt Uu Vv Ww Xx yy $z z$ 01234567890}

Gambar 24 Typeface Mandau oleh Sopa Sudinar, 2012, terinspirasi dari senjata tradisonal Mandau. Sumber: http://luc.devroye.org/SopaSudinarMandau-2012.jpg

Gambar 25 Typeface FTF Ahlan Ve Arabez, dengan penggayaan aksara Arab Sumber: dafont.com 


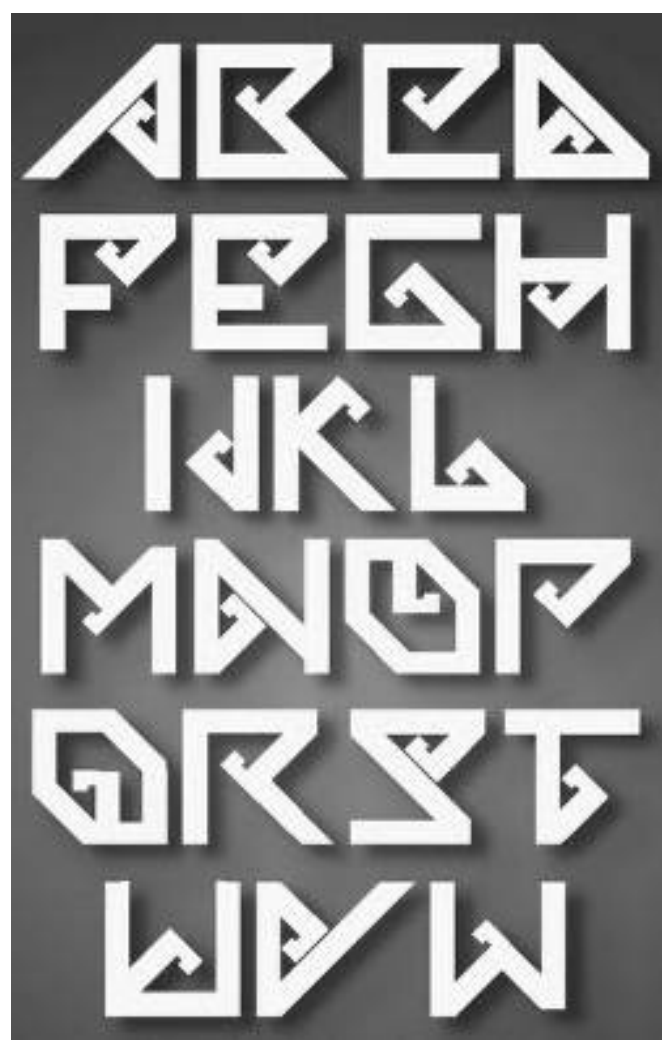

Gambar 26 Typeface Songket Minang oleh Tommy Sitanggang, 2009, terinspirasi dari motif songket Minang.

Sumber: http://luc.devroye.org/Tommy SitanggangSongketMinang-2009.jpg

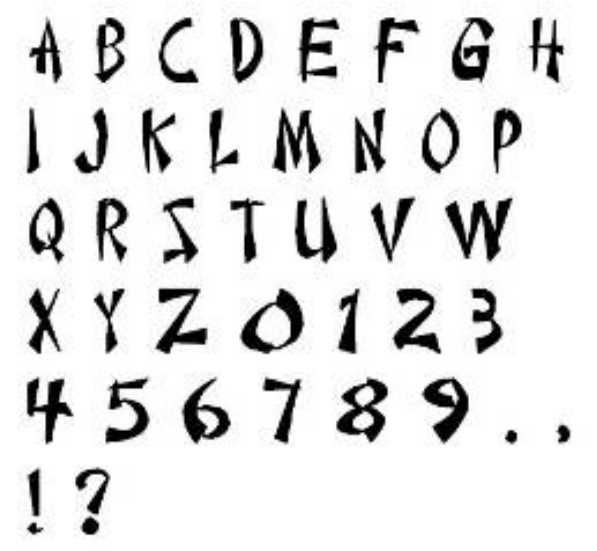

Gambar 27 Typeface Chinese Takeaway Sumber: http://www.dafont.com/chinesetakeaway.font

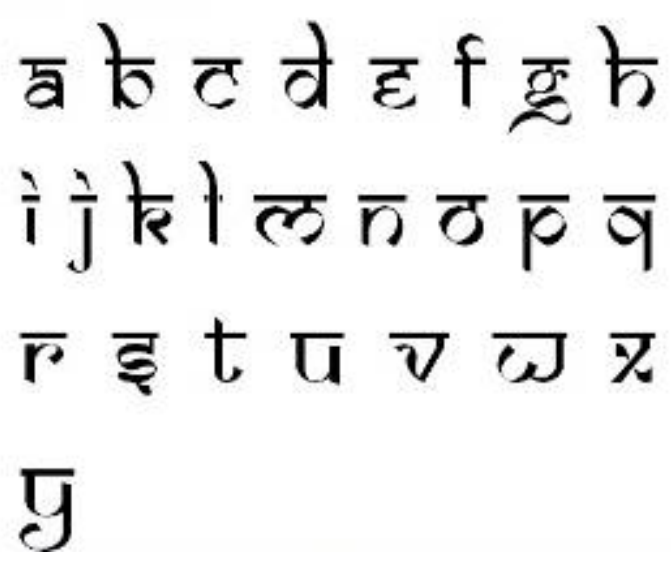

Gambar 28 Typeface Samarkan dengan penggayaan aksara India

Sumber: dafont.com

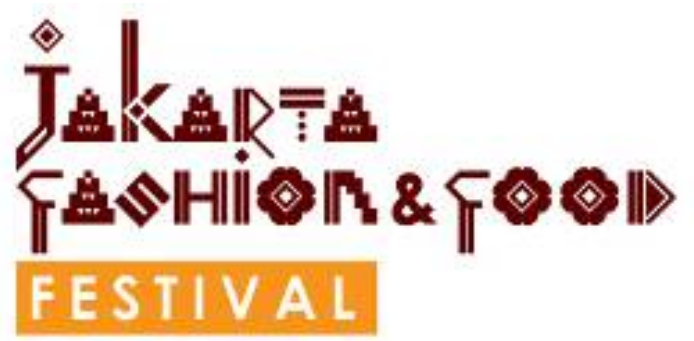

Gambar 29 Logo Jakarta Fashion \& Food Festival oleh Gabriel Latupeirissa, 2014, terinspirasi oleh ragam hias pada kain tradisional Indonesia yaitu Tenun Timor, Ulos Batak, Songket Palembang and Batik Jawa

Sumber:

https://www.behance.net/gallery/14567863/JakartaFashion-Food-Festival

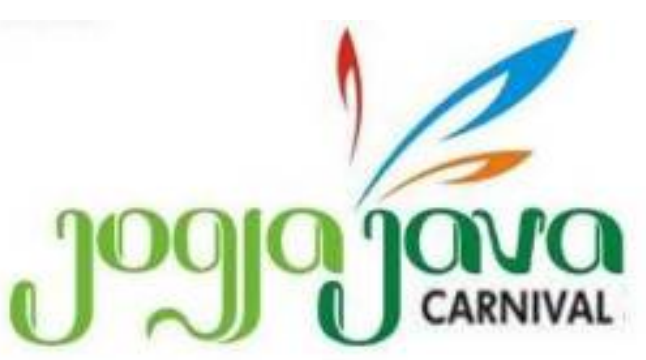

Gambar 30 Logo Jogja Java Carnival dengan teks/aksara latin gaya aksara Jawa

Sumber: http://pariwisata.jogjakota.go.id/ 


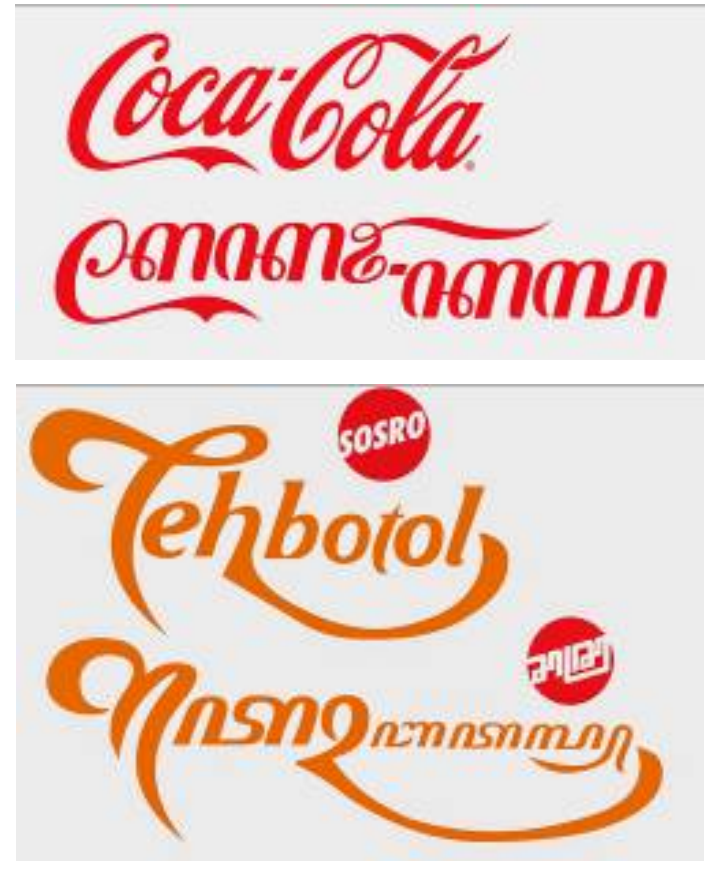

Gambar 31 Eksplorasi alih rupa logotype ke dalam aksara Jawa oleh Aditya Bayu Sumber:

http://www.fontasticindonesia.blogspot.ca/search/label/ Aksara\%20Nusantara?\&max-results $=3$

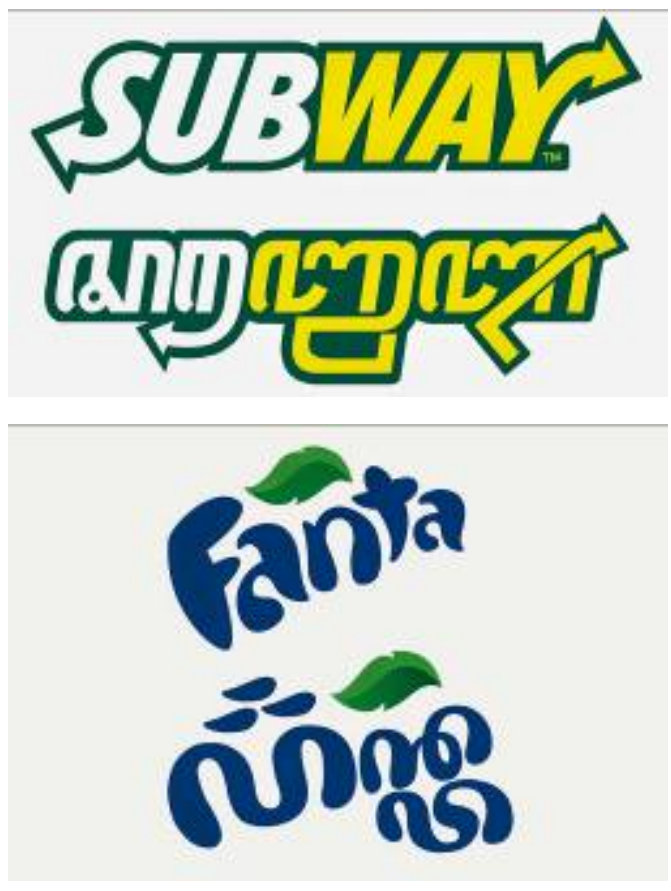

Gambar 32 Eksplorasi alih rupa logotype ke dalam aksara Jawa oleh Aditya Bayu Sumber:

http://www.fontasticindonesia.blogspot.ca/search/label/ Aksara\%20Nusantara?\&max-results=3

\section{DAFTAR PUSTAKA}

\section{Buku}

[1] Ricoeur, Paul. 2012. Teori Interpretasi. Yogyakarta: IRCiSoD

[2] Sihombing, Danton. 2001. Tipografi dalam Desain Grafis. Jakarta: Gramedia

[3] Rustan, Surianto. 2011. Font \& Tipografi. Jakarta: PT. Gramedia Pustaka Utama

[4] Strizver, Ilene. 2006. Type rules!: The Designer's Guide To Professional Typograph. United States of America: John Wiley \& Sons, Inc.

[5] Widyatmoko, dkk. 2010. Aksara-Aksara Nusantara. Yogyakarta: ZAT Publishing.

\section{Laporan TA}

[1] Laporan Tugas Akhir Perancangan, DKV ISI Yogyakarta, 2012

[2] Laporan Tugas Akhir Perancangan, DKV ISI Yogyakarta, 2013

\section{Internet}

[1] http://www.desainstudio.com/2011/04/k umpulan-font-khas-indonesia-karyaanak.html)

[2] http://www.dafont.com/parangrusak. font)

[3] dafont.com

[4] http://www.ffonts.net/Balinese-FamilyNormal.font)

[5] http://www.desainstudio.com/2011/04/k umpulan-font-khas-indonesia-karyaanak.html

[6] http://www.myfonts.com/fonts/aawm/ga ruda/

[7] https://www.behance.net/gallery/160867 33/Kutai-Typeface

[8] https://www.behance.net/gallery/139625 85/GADANG-FONT 
[9] https://www.behance.net/gallery/160867 33/Kutai-Typeface

[10] https://www.behance.net/gallery/210722 8/Balinese-Deva

[11] http://www.fontspace.com/gunarta/bouti ques-of-merauke

[12] http://lontaratypeface.blogspot.com/2011 /06/nusantara-original-lontaratypeface.html

[13] https://www.behance.net/gallery/148672 97/Barong-Typeface

[14] http://www.fontspace.com/gunarta/antiq ue-paleoindonesia

[15] http://www.dafont.com/sangkuriang.font

[16] http://www.dafont.com/minangkabau.fo $\mathrm{nt}$

[17] http://www.behance.net/gallery/Kaliman $\tan$-font/11425621

[18] https://www.behance.net/gallery/166585 45/Gunungan-Typeface

[19] http://luc.devroye.org/JihadYanuarCalligrang-2013.jpg

[20] http://luc.devroye.org/NurAlfiFontGolok-2013.jpg

[21] http://luc.devroye.org/SopaSudinarMandau-2012.jpg

[22] http://luc.devroye.org/Tommy Sitanggang-SongketMinang-2009.jpg

[23] https://www.behance.net/gallery/145678 63/Jakarta-Fashion-Food-Festival

[24] http://pariwisata.jogjakota.go.id/

[25] http://www.fontasticindonesia.blogspot.c a/search/label/ Aksara\%20Nusantara?\&max-results=3

[26] http://www.dafont.com/chinesetakeaway.font 